\title{
Recursos naturais nas Relações Internacionais: O precedente do Brasil na Segunda Guerra Mundial
}

\author{
Márcio Schiefler Fontes ${ }^{1}$
}

\begin{abstract}
Resumo
O ingresso do Brasil na Segunda Grande Guerra foi marcado pela disputa de influência na América do Sul entre a Alemanha hitlerista e os Estados Unidos, com os quase ilimitados recursos naturais brasileiros como ingredientes principais, especialmente borracha, ferro, manganês, algodão, café e açúcar. Sob Vargas desde 1930, o Brasil mostrou-se capaz de equilibrar-se no tabuleiro e dele tirar proveito, a exemplo da Companhia Siderúrgica Nacional.
\end{abstract}

Palavras-chave: Relações internacionais; recursos brasileiros; Segunda Guerra Mundial; ditadura Vargas.

Los Recursos Naturales en las Relaciones Internacionales: el precedente de Brasil en la Segunda Guerra Mundial

\section{Resumen}

El ingreso de Brasil en la Segunda Guerra Mundial fue marcado por la lucha de influencias en América del Sur entre la Alemania hitleriana y los Estados Unidos, con los vastos recursos naturales brasileños como ingredientes, especialmente caucho, hierro, manganeso, algodón, café y azúcar. Gobernado por Vargas desde 1930, Brasil se mostró capaz de encontrar un equilibrio en el campo de las relaciones internacionales y de sacar provecho de la situación, por ejemplo con la construcción de la Compañía Siderúrgica Nacional. Palabras clave: Relaciones internacionales; recursos naturales; Segunda Guerra Mundial; Dictadura de Vargas.

\section{Natural resources and international relations: Brazil as a precedent in World War II}

\section{Abstract}

Brazil's entry into World War II was marked by a dispute between Hitler's Germany and the United States over the two countries' influence in Brazil, with Brazil's vast natural resources such as rubber, iron, manganese, cotton, coffee and sugar fuelling the quarrel. Governed by President Vargas from 1930, Brazil revealed its ability to maintain its balance in international relations and even benefit from such a position, as exemplified by the formation of the Companhia Siderúrgica Nacional [National Steel Company].

Keywords: International relations; natural resources; World War II; the Vargas dictatorship.

\footnotetext{
${ }^{1}$ Mestre em Estudos da Tradução pelo Centro de Comunicação e Expressão da Universidade Federal de Santa Catarina (2008). Juiz Instrutor no Supremo Tribunal Federal (Gabinete do Ministro Teori Zavascki). É Juiz de Direito em Santa Catarina e Professor da Escola da Magistratura do Estado de Santa Catarina (Direito Constitucional e Direito Processual). E-mail: schiefler.fontes@tjsc.jus.br
} 
Les ressources naturelles dans les relations internationales: le précédent du Brésil lors de la Seconde Guerre mondiale

\section{Résumé}

L'entrée du Brésil dans la Seconde Guerre mondiale a été marquée par un conflit d'influence en Amérique du Sud entre l'Allemagne hitlérienne et les États-Unis, avec pour toile de fond les immenses ressources naturelles brésiliennes, comme le caoutchouc, le fer, le manganèse, le coton, le café et le sucre. Dirigé par Getúlio Vargas depuis 1930, le Brésil avait réussi à trouver un certain équilibre au sein des relations internationales et même à en tirer profit, comme dans le cas de la création de la Compagnie sidérurgique nationale.

Mots-clés : Relations internationales ; ressources naturelles ; Seconde Guerre mondiale ; dictature Vargas.

\section{自然资源与国际关系：巴西在第二次世界大战中的纵横}

摘要:

巴西参加二战是当时希特勒德国和美国争夺南美的影响力的结果, 因为巴西自然资源丰富, 盛产橡胶, 铁, 锰 , 棉花, 咖啡和蔗糖。瓦尔加斯

(Vargas)

政府从1930年开始, 就在俩大国之间寻找平衡, 利用大国之间的矛盾, 以争取最大国家利益。比如巴西国际 钢铁公司就是这种政策的结果。

关键词：国际关系，自然资源，二次大战，瓦尔加斯独裁政府

\section{Introdução}

Não é de agora que os recursos naturais exercem influência nas relações internacionais. Enquanto Renouvin e Duroselle ${ }^{2}$ reportam-se às forças profundas - nas quais se incluem as condições físicas e geográficas em que se inserem as nações - a orientar os Estados nacionais, o ex-secretário de Estado norte-americano Colin Powell ${ }^{3}$ invoca o conceito de "parceria" para expor a presença militar dos Estados Unidos em áreas cujos recursos naturais são vitais para os interesses daquele país. Também no caso do Brasil - e principalmente, porque país de vastos recursos, tanto naturais como humanos - os recursos naturais se têm mostrado peça fundamental em sua política internacional. Ainda hoje estudiosos de peso aqui ${ }^{4}$ e no exterior ${ }^{5}$ têm realçado o papel

\footnotetext{
${ }^{2}$ Renouvin, Pierre; Duroselle, Jean-Baptiste (1967). Introdução à história das relações internacionais, São Paulo: Difusão Européia do Livro, p. 11-34.

${ }^{3}$ Powell, Colin L. (2004). "A strategy of partnership". In: Foreign Affairs, Nova lorque, v. 83, n. 1, p. 22-34, jan./fev.

${ }^{4}$ Almeida, Paulo Roberto de (2002). Os primeiros anos do século XXI: o Brasil e as relações internacionais contemporâneas, São Paulo: Paz e Terra, p. 237.
} 
desses recursos - mormente sua exportação - nas relações brasileiras com 0 estrangeiro.

Nossa história é repleta de exemplos de como os recursos naturais foram fundamentais para o delineamento das relações nacionais com o exterior. Já o deflagrar do processo de colonização, com as capitanias hereditárias, viu-se marcado pela exploração do pau-brasil ${ }^{6}$, agora praticamente extinto. Não há nada de significativo, portanto, em partir da constatação de que a ponderação dos recursos naturais no contexto internacional é fundamental para a compreensão das relações entre países, começando pelo Brasil.

Desponta com desenvoltura um peculiar exemplo dessa realidade, cuja importância na história brasileira recente lhe confere lugar de destaque no estudo da influência dos recursos naturais na cena internacional: o ingresso do Brasil na Segunda Guerra Mundial (1939-1945). Em verdade, a disputa dos recursos brasileiros por Estados Unidos e Alemanha no limiar do conflito constitui chamativo precedente da movimentação do País no tabuleiro do jogo das potências mundiais, interessadas - como sempre estiveram nos recursos naturais dos países periféricos.

O assédio e a necessidade desses recursos nas relações internacionais não são novos nem inéditos, como de plano demonstra a constante disputa pelo petróleo do Oriente Médio. As relações internacionais em muito se definem pela contenda entre nações por recursos naturais existentes em terceiros países, agora como no passado.

No caso brasileiro, como dito, há precedente específico dessa disputa, ocorrida entre Estados Unidos e Alemanha na década de 1930, às vésperas da Segunda Guerra Mundial, pelo que um estudo concreto e mais presente na realidade brasileira se faz cabível. Nada mais oportuno a essa problemática, então, que vislumbrar o panorama do período imediatamente anterior ao início das hostilidades, capaz de demonstrar a importância das matérias-primas brasileiras no comércio de exportação tanto para a Alemanha quanto para os Estados Unidos, potências que na sequência se achariam em lados opostos no âmbito de uma conflagração militar de proporções cataclísmicas.

Dessa forma, seria possível evidenciar também, por exemplo, o papel da usina siderúrgica de Volta Redonda no processo nacional de industrialização, a partir do

\footnotetext{
${ }^{5}$ Hakim, Peter (2004). The reluctant partner. In: Foreign Affairs, Nova lorque, v. 83, n. 1, p. 114-23, jan./fev.

${ }^{6}$ Lafer, Celso (2001). A identidade internacional do Brasil e a política externa brasileira: passado, presente e futuro, São Paulo: Perspectiva, p. 27.
} 
emprego do ferro brasileiro, como consequência da política brasileira na disputa observada, e, finalmente, examinar o envolvimento do Brasil na guerra como resultado do ambiente internacional da época, o qual, como o de hoje, é fortemente influenciado por necessidades econômicas marcadas pela carência de recursos naturais.

\section{Recursos naturais brasileiros na década de 1930}

Para alguns, a entrada do Brasil na guerra ao lado dos Aliados era uma determinação histórica, uma decisão consumada antecipadamente a partir do quadro econômico posto já no início dos anos $1930^{7}$. Diferentemente, outros sustentam ter sido a guerra contra o Eixo uma livre e consciente opção do governo brasileiro - ainda que estimulado por circunstâncias particulares ${ }^{8}$.

Os elementos naturais da pauta de exportação, tanto recursos naturais propriamente ditos como produtos primários, eram o sustentáculo principal, por assim dizer, de um país que não podia, dadas as suas dimensões geográficas e demográficas, ser ignorado no jogo - já avançado - das potências mundiais que desembocaria na guerra em 1939.

De maneira geral, o Brasil seguia estruturado em suas características primordialmente agrícolas: $70 \%$ de sua população residia no campo, com grande parte dela analfabeta ${ }^{9}$; Rio de Janeiro e São Paulo, no entanto, já ultrapassavam a casa do milhão de habitantes ${ }^{10}$. Depois da crise de 1929, quando as exportações brasileiras caíram pela metade ${ }^{11}$, a velha estrutura agrária brasileira tentava reerguer-se.

De outro lado, embora a década de 1930 tenha experimentado um processo de industrialização um tanto mais acentuado que as décadas anteriores, isso só seria

\footnotetext{
${ }^{7}$ Alves, Vágner Camilo (2002). O Brasil e a Segunda Guerra Mundial: história de um envolvimento forçado, Rio de Janeiro: PUC-Rio; São Paulo: Loyola, p. 42.

${ }^{8}$ Seitenfus, Ricardo (2003). O Brasil vai à guerra: o processo do envolvimento brasileiro na Segunda Guerra Mundial. 3. ed., São Paulo: Manole, p. 311.

${ }^{9}$ Brasil (1941-1945). Anuário Estatístico, Ano VI, Rio de Janeiro: IBGE, p. 29/1945 apud Alves, Vágner Camilo (2002). O Brasil e a Segunda Guerra Mundial: história de um envolvimento forçado, Rio de Janeiro: PUC-Rio; São Paulo: Loyola, p. 54.

${ }_{10}^{10}$ Brasil (1939-1940). Anuário Estatístico, Ano V, Rio de Janeiro: IBGE, p. 1294 e 1297-1298/1940 apud Alves, Vágner Camilo (2002). O Brasil e a Segunda Guerra Mundial: história de um envolvimento forçado, Rio de Janeiro: PUC-Rio; São Paulo: Loyola, p. 54.

${ }_{11}$ Abreu, Marcelo de Paiva (1995). "O Brasil e a economia mundial (1929-1945)". In: Fausto, Boris (Org.) (1995). O Brasil republicano. v. 4. Economia e cultura (1930-1964). 3. ed., Rio de Janeiro: Bertrand Brasil, p. 17. (História Geral da Civilização Brasileira)
} 
perceptível a partir de seu final, ou melhor, já na década de 1940, dado que o setor primário, ainda em 1939, correspondia a $66 \%$ de toda a atividade econômica nacional ${ }^{12}$.

O café, não como há negar, mantinha sua majestade, movimentava fortunas; no entanto, sua participação na economia brasileira, a par de haver iniciado lenta e contínua trajetória negativa, declinava drasticamente. Se até aproximadamente 1920 o café chegou a responder sazonalmente por 70\% de nossas exportações, após a crise de 1929 dificilmente voltaria a patamares superiores à metade da pauta exportadora, com queda ainda mais brusca no período imediatamente posterior - note-se, todavia, que no período especialmente relevante entre 1934 e 1939 se manteve num nível pouco abaixo dos $50 \% \%^{13}$.

Apesar dos valores que representava e do consumo sempre crescente que ensejava, o café, produto supérfluo que é e pela multiplicação de países produtores, não entra no âmago da questão, marcadamente ao se observar a corrida industrial e armamentista que precedeu a guerra. Mais além, a Primeira Guerra Mundial servira de flagrante demonstração da total falta de cerimônia dos países "aliados" do Brasil notadamente Reino Unido e Estados Unidos - em privá-lo de sua principal fonte de renda $^{14}$.

Para o aqui exposto convergem sobremaneira, em outra margem, produtos que significavam, para países como Estados Unidos e Alemanha, requisitos indispensáveis ao bom funcionamento de suas economias, altamente industrializadas e baseadas em incentivo ao consumo individual. No caso brasileiro ${ }^{15}$, despontam inicialmente quatro, dois recursos naturais por assim dizer e dois produtos agrícolas: a borracha, o algodão, 0 açúcar e o ferro. Os três primeiros pelo volume da produção nacional já então existente; o último pelo valor estratégico.

A borracha do látex era, em certo sentido, o menos importante deles. Já em 1922 Winston Churchill, então secretário britânico das colônias, nomeara comissão chefiada por James Stevenson para estudar maneiras de elevar o preço do produto, que em 1921

\footnotetext{
${ }_{12}^{12}$ Buescu, Mircea (1977). Evolução econômica do Brasil, São Paulo: Brasiliense, p. 184.

${ }^{13}$ Ibidem, p. 158.

14 Fausto, Boris (1997). "Expansão do café e política cafeeira". In: Fausto, Boris (Org.) (1997). O Brasil republicano. v. 1. Estrutura de poder e economia. 6. ed., Rio de Janeiro: Bertrand Brasil, p. 229. (História Geral da Civilização Brasileira)

15 "No final da década [de 1920] oito produtos primários ainda representavam 90\% em valor do total das exportações: café (cerca de $70 \%$ do total), açúcar, cacau, algodão, mate, tabaco, borracha, couros e peles". Abreu, Marcelo de Paiva (1995). Op. Cit, p. 13.
} 
caíra "ao mínimo de oito pence por libra"16. Isso porque, no caminhar do ciclo da extração do látex na Amazônia, as colônias inglesas e holandesas assumiram a ponta da produção mundial, a qual, pelo menos até o começo do "entre-guerras" (1918-1939), conhecia significativa presença brasileira.

A crescente importância da borracha do látex na pauta brasileira de exportações, da segunda metade do século XIX até seu virtual desaparecimento na década de 1930, refletiu uma vez mais circunstâncias externas. O emprego do produto da seringueira na fabricação de material bélico e na construção naval, com a descoberta do processo de vulcanização por Charles Goodyear, em 1839, e Thomas Hancock, em 1842, não cessaria de aumentar, ao lado do uso na confecção de objetos de uso doméstico e diário, principalmente depois da invenção do pneumático em $1890^{17}$.

O Brasil responderia a esse estímulo quase imediatamente e persistiria nele até depois de deixar de ser requisitado. A borracha brasileira só seria definitivamente sepultada, enquanto ciclo econômico de relevância, depois do aparecimento da borracha sintética, já depois da Segunda Grande Guerra. Levas de dezenas de milhares de brasileiros, nordestinos em sua maioria, seguiram para a Amazônia numa romaria - como se revelaria mais tarde - macabra, a fim de atender à nova demanda mundial por um recurso tornado imprescindível. É verdade que não se confiam nas estatísticas oficiais acerca do número de migrantes que se deslocaram desde o final do século XIX até o início do século $X X$, mas Celso Furtado $^{18}$ estimou que não tenha sido inferior a meio milhão de pessoas.

A situação do algodão era diferente. De importância fundamental na história do capitalismo e no desenvolvimento de potências de primeira grandeza, como os Estados Unidos $^{19}$, o algodão - matéria-prima essencial às indústrias e ao mercado interno dos países centrais - desempenhará papel de destaque no jogo de influências disputado por alemães e estadunidenses às vésperas da Segunda Guerra Mundial. Segundo Caio Prado Júnior, "ao estalar a Segunda Guerra Mundial, a exportação do algodão brasileiro

\footnotetext{
${ }^{16}$ Prado, Maria Lígia Coelho; Capelato, Maria Helena Rolim (1997). "A borracha na economia brasileira da Primeira República”. In: Fausto, Boris (Org.) (1997). O Brasil republicano. v. 1. Estrutura de poder e economia. 6. ed., Rio de Janeiro: Bertrand Brasil, p. 305. (História Geral da Civilização Brasileira)

${ }_{17}$ Prado, Maria Lígia Coelho; Capelato, Maria Helena Rolim (1997). Op. Cit., p. 288.

${ }^{18}$ Furtado, Celso (1961). Formação econômica do Brasil. 4. ed., Rio de Janeiro: Fundo de Cultura, p. 153.

19 "Chegou a representar mais da metade do valor das exportações dos Estados Unidos". Furtado, Celso (1961). Op. Cit., p. 124.
} 
vinha efetivamente em aumento contínuo, alcançando em 1939 o alto nível de 323.529 toneladas" 20 .

Muito embora o ciclo do algodão estivesse moribundo nas primeiras décadas do século XX, a partir do início da década de 1930 o Brasil seria palco de novo surto algodoeiro, semelhante ao provocado pelas guerras de independência dos Estados Unidos. Mais precisamente desde 1934 e até a deflagração da guerra, o País aparece novamente entre os grandes fornecedores mundiais, chegando a praticamente multiplicarse a produção de ano para ano. Havia, é verdade, condições ideais para aquela produção, a começar pela já mencionada decadência da lavoura cafeeira, oferecendo, em novo dizer de Caio Prado Júnior ${ }^{21}$, “grandes áreas de terras aproveitáveis e já preparadas, mão-de-obra abundante, recursos técnicos (transportes, aparelhamento agronômico e comercial) que se podiam facilmente aproveitar para a nova cultura". 0 diferencial, entretanto, veio novamente de fora: política de valorização dos Estados Unidos, protecionismo britânico e ânsia de Alemanha e Japão por novos fornecedores à margem do domínio de seus virtuais inimigos, aliás influenciando diretamente, por meio das respectivas colônias no Brasil, a produção brasileira.

Outro produto primário de grande presença na economia brasileira na primeira metade do século XX era o açúcar, velho conhecido, cuja produção emanava condições peculiares, não só em razão de voltar-se num primeiro momento ao mercado interno, mas em virtude de sua abrupta e temporária expulsão do mercado mundial do início do século até a década de $1930^{22}$.

Desde as três últimas décadas do século XIX, o crescimento industrial e a expansão do consumo de café, chá e chocolate - mormente na Alemanha, no Reino Unido e nos Estados Unidos - propiciaram um novo salto produtor açucareiro, cuja finalidade era atender a uma demanda que elegera o açúcar como nova fonte primaz de energia calórica das camadas populares. No entanto, a concorrência do açúcar produzido nas Antilhas (antigo rival do brasileiro), bem assim daquele extraído da beterraba na Europa, além da guerra de tarifas que se seguiu à referida expansão, frearam os efeitos da difusão do consumo. A exportação nacional só recuperaria um pouco do vigor justamente

\footnotetext{
${ }^{20}$ Prado Júnior, Caio (1998). História econômica do Brasil. 45. reimpr., São Paulo: Brasiliense, p. 293.

${ }^{21}$ Ibidem, p. 276.
} 
a partir de novo incremento na demanda alemã com a aproximação da guerra em 1939, tal qual havia acontecido entre 1917 e 1922 com a contração do mercado produtor em razão da Primeira Guerra Mundial ${ }^{23}$. Neste último item, fica suficientemente evidenciada a brutal dependência do Brasil, economia agrário-exportadora, ao mercado produtor mundial e às variações da oferta, mesmo no século $X X$ - pois não faltam exemplos disso nos séculos anteriores, como a retomada da expansão açucareira ocorrida em razão da revolução de 1789 no $\mathrm{Haiti}^{24}$.

A introdução ao horizonte exportador de recursos naturais e produtos primários que se esboçava na década de 1930 encontra fim no ferro, recurso natural imprescindível à indústria, principalmente ao segmento de base, cuja participação na produção militar é decisiva. Todavia, as dificuldades de acesso impediram que a procura internacional atribuísse ao Brasil papel importante na exportação de ferro em tempos anteriores. Isso não quer dizer, evidentemente, que tais agentes econômicos o desprezassem. Caio Prado Júnior assinalou ${ }^{25}$ :

Desde as vésperas da guerra de 1914, os grandes trustes siderúrgicos internacionais procuram obter o domínio das jazidas brasileiras de ferro, o que efetivamente conseguiram; mas isto com o fim principal de guardá-las para um futuro remoto. Não as exploram em escala apreciável, e é somente depois de 1930 que o Brasil começa efetivamente a exportar minério.

No comércio internacional, o Brasil, como outros países frutos da expansão europeia, nas palavras de Warren Dean "tirava proveito dos seus ilimitados recursos naturais e da sua mão-de-obra barata" ${ }^{26}$. Nada mais previsível. No caso do ferro e da indústria metalúrgica, contudo, o País vivia uma situação paradoxal: ao tempo em que possuía aproximadamente $22 \%$ das reservas mundiais ${ }^{27}$, a produção irrisória, em razão também da inexistência de reservas de carvão próximas às reservas de ferro, atrasava pateticamente o setor mais imprescindível ao progresso industrial.

\footnotetext{
${ }^{22}$ Gnaccarini, José C. (1997). "A economia do açúcar. Processo de trabalho e processo de acumulação". In: Fausto, Boris (Org.) (1997). O Brasil republicano. v. 1. Estrutura de poder e economia. 6. ed., Rio de Janeiro: Bertrand Brasil, p. 311. (História Geral da Civilização Brasileira)

${ }^{23}$ Ibidem.

${ }^{24}$ Furtado, Celso (1961). Op. Cit., p. 110.

${ }^{25}$ Prado Júnior, Caio (1998). Op. Cit., p. 275.

${ }^{26}$ Dean, Warren (1997). "A industrialização durante a República Velha". In: Fausto, Boris (Org.). (1997). O Brasil republicano. v. 1. Estrutura de poder e economia. 6. ed., Rio de Janeiro: Bertrand Brasil, p. 251. (História Geral da Civilização Brasileira)

${ }^{27}$ Prado Júnior. Caio (1998). Op. Cit., p. 275.
} 
Até 1920, os altos-fornos brasileiros, fundados ainda sob os auspícios do Segundo Império, tinham fechado, à exceção de um, ao arrepio da explosão no consumo de ferro, que subira, por exemplo, de 130.000 para 580.000 toneladas entre 1903 e $1913^{28}$. Na década de 1930, o mercado continuava a ser abastecido pela produção estrangeira, especialmente artigos metalúrgicos como fios, chapas galvanizadas, folhas de estanho, eixos e rodas, barras e tirantes ${ }^{29}$.

A questão do ferro e da metalurgia no Brasil, às portas da Segunda Guerra Mundial, expunha gritante contradição: dono de imensas e praticamente inexploradas jazidas do metal, o Brasil assistia a sua industrialização ser amarrada justamente pela falta de produtos derivados do ferro.

Quando a aproximação do combate provocasse o desvio total e definitivo do mercado internacional de produtos metalúrgicos para as fábricas de armas na Europa e nos Estados Unidos, o que era apenas uma questão de tempo, a situação de estrangulamento industrial do Brasil ficaria insustentável. Essa questão siderúrgica é de cabal importância para a compreensão da política externa brasileira no período.

\section{Políticas comerciais antagônicas}

Para Eric Hobsbawm, o mundo chegou à terceira década do século XX - o "breve" à espera da nova guerra ${ }^{30}$. A essa altura dos acontecimentos, os contendores de um conflito de proporções catastróficas, cada vez mais presente, alinhavam-se lenta porém decididamente: a Itália fascista dera suporte ideológico à ascensão do nacional-socialismo na Alemanha, que se impunha ameaçadoramente à Europa Oriental, aliada da França e do Reino Unido, ambos - juntamente com os Estados Unidos - representando as democracias liberais e conservadoras alvo do fogo ideológico do internacional-socialismo da Rússia, cuja apreensão com o poderio industrial e militar hitlerista a fazia um tanto mais suave no trato com os ocidentais (a Rússia comunista e a Alemanha nazista entraram de mãos dadas na guerra). Ao longe, um Japão militarizado, perseguindo um

\footnotetext{
${ }^{28}$ Dean, Warren (1997). Op. Cit., p. 257.

29 Ibidem.

30 Hobsbawm, Eric (1995). Era dos extremos: o breve século XX: 1914 - 1991. Tradução de Marcos Santarrita, São Paulo: Companhia das Letras, p. 43.
} 
expansão territorial agressiva, observava atento o desenrolar da cena internacional, sem ceder passo em sua violenta penetração da China.

O Brasil, do lado ocidental do Atlântico, testemunhava inerme o desfecho da crise europeia. Contudo, os anos 1930 revelar-se-iam decisivos para o desenvolvimento da situação política, econômica e social do País nas décadas subsequentes. Mais além do crash da Bolsa de Nova lorque em 1929 e da depressão econômica que se lhe seguiu, a patente crise do livre comércio - ricamente ilustrada no caso do Império Britânico pelo abandono do padrão-ouro em 1931 e pela adoção do protecionismo escancarado a partir da Conferência de Ottawa em 1932, mal disfarçado pelo discurso das "preferências imperiais" - dava o tom do acirramento das lutas entre os Estados nacionais ${ }^{31}$.

A Alemanha é o primeiro cenário que avulta. Governada pelo Partido NacionalSocialista desde 1933, tinha como objetivo inegociável a autossuficiência, entendida como controle irresistível de mercados que fornecessem os recursos naturais e os produtos primários que a Alemanha necessitasse e absorvessem seu excedente industrial. Para isso, deveria ser formado o Lebensraum - ou espaço vital - pela expansão territorial à custa de países menores do leste da Europa. Não obstante a nostalgia de glória militar e grandeza imperial de sua casta dirigente, a economia alemã, no curto prazo, dependia desesperadamente do mercado internacional para despachar seus produtos manufaturados e incorporar matéria-prima do estrangeiro ${ }^{32}$.

Já em 1920, aliás, John Maynard Keynes, na análise crítica que fez das duras imposições do Tratado de Versalhes, acentuara a necessidade absoluta da Alemanha por recursos naturais provindos do exterior, fato de qualquer forma percebido muito antes de sua chegada ao topo das potências industriais ${ }^{33}$. A economia alemã, portanto, exigia íntimas relações com países cujo perfil econômico fosse de importação de manufaturas e exportação de recursos naturais; em outras palavras, a Alemanha ansiava por fazer trocas comerciais com países cujas economias fossem complementares à alemã, circunstâncias que qualificavam em cheio o Brasil.

\footnotetext{
${ }^{31}$ Alves, Vágner Camilo (2002). O Brasil e a Segunda Guerra Mundial: história de um envolvimento forçado, Rio de Janeiro: PUC-Rio; São Paulo: Loyola, p. 46.

32 Ibidem, p. 49.

${ }^{33}$ Keynes, John Maynard (2002). As conseqüências econômicas da paz. Tradução de Sérgio Bath, Brasília: Universidade de Brasília, Instituto de Pesquisa de Relações Internacionais; São Paulo: Imprensa Oficial do Estado de São Paulo, p. 8.
} 
Vários elementos presentes no maior país do Sul despertaram o interesse do Terceiro Reich. Numerosos alemães deslocaram-se da Europa para o Brasil entre o início do século XIX e o começo do século XX. Em fins da década de 30, de uma população brasileira total de menos de 40 milhões de habitantes, destacavam-se quase 1 milhão de pessoas nas comunidades chamadas "teuto-brasileiras" - alemães ou descendentes diretos de alemães, cuja expressiva maioria sequer falava português - concentrados nos três Estados meridionais, mais ostensivamente em Santa Catarina e no Rio Grande do $\mathrm{Sul}^{34}$. Os esforços do governo brasileiro na década de 1930, no sentido de prover as comunidades germânicas de educação nacionalizada, ainda eram discretos, apesar de já se fazerem sentir. No início da década seguinte, por exemplo, o número de brasileiros natos utilizando o alemão como língua principal no meio familiar ainda era de cerca de $700 \mathrm{mil}^{35}$.

Em contraste, os Estados Unidos - já então parceiros econômicos tradicionais do Brasil - trilhavam caminho oposto ao da Alemanha, acentuando o protecionismo predominante depois de 1930: o algodão, por exemplo, por motivos políticos internos, sofreria intensa valorização artificial a partir de 1933, o que contrariava frontalmente a expectativa brasileira de exportação para aquele mercado ${ }^{36}$. $\mathrm{O}$ tratamento privilegiado que o governo dos Estados Unidos ofertou ao algodão de seu próprio país teve efeito automático: como destaca Caio Prado Júnior, no final da década de 1930 "os principais compradores do Brasil eram as potências do Eixo: Alemanha e Japão"37.

Curiosamente, entretanto, a exceção dessa regra geral era a América Latina, justamente em virtude da complementaridade da região às economias industriais. Os interesses estadunidenses apresentavam-se abrangentes e de longo prazo, no intuito de consolidar sua presença dominante; os interesses alemães eram incisivos, de curto prazo, almejando livrar o Reich da escassez asfixiante de matérias-primas. O Brasil, por motivos particulares a cada uma dessas potências, convertia-se em mira de ambas, que no quadro geral se colocavam em rota de colisão ${ }^{38}$.

\footnotetext{
${ }^{34}$ Alves, Vágner Camilo (2002). Op. Cit., p. 63.

35 Rodrigues, José Honório; Seitenfus, Ricardo (1995). Uma história diplomática do Brasil, 1531-1945, Rio de Janeiro: Civilização Brasileira, p. 381.

${ }^{36}$ Prado Júnior, Caio (1998). Op. Cit., p. 293.

37 Ibidem.

${ }^{38}$ Alves, Vágner Camilo (2002). Op. Cit., p. 53.
} 
$\mathrm{Na}$ caserna, a mencionada questão siderúrgica, que despertava atenção governamental desde a Primeira República ${ }^{39}$, também se fazia sentir. Os militares estavam conscientes de que o patamar de desenvolvimento nacional não permitia produção além de munição e equipamentos individuais; material bélico pesado teria de ser adquirido do exterior ${ }^{40}$. Assim, a relação comercial Brasil-Alemanha prometia mais, como de fato aconteceu a partir de 1934, quando uma comissão alemã visitou o Brasil, com o objetivo de firmar as trocas comerciais com base nos chamados "marcos de compensação", que propiciaram que o Brasil tivesse consolidado, já em 1935, o posto de principal parceiro comercial da Alemanha na América Latina ${ }^{41}$.

A relação de comércio entre Brasil e Alemanha passou a apresentar-se às claras como expedientes de troca, na direção do que apontavam as características de suas economias: recursos naturais por produtos industrializados. A permuta que daí se delineava tinha motivo concreto, pois o governo alemão não possuía divisas em abundância, uma vez que sua economia, como já demonstrado, requeria continuamente amplos gastos na compra de produtos naturais ${ }^{42}$.

O Reich - que na corrida armamentista podia dar-se ao luxo de entregar o que quisesse o governo brasileiro, pobre de horizontes em termos militares - ansiava pelas matérias-primas do Brasil, algodão à frente, ferro em segundo lugar. Por seu turno, a Itália - embora sua influência ${ }^{43}$ nos rumos políticos brasileiros fosse rigorosamente anulada pelo atabalhoado apoio empenhado ao integralismo, logo que possível defenestrado por Vargas $^{44}$ - seria outra a entregar material bélico em troca de matéria-prima, algodão em primeiro lugar ${ }^{45}$. Isso ocasionou a configuração de panorama singular, como mostra Vágner Camilo Alves:

Em fins de 1936 foram feitos contatos com a empresa alemã Krupp para aquisição de peças de artilharia, tanto para defesa costeira como para guerra antiaérea.

\footnotetext{
39 Tronca, Ítalo (1996). "O Exército e a industrialização: entre as armas e Volta Redonda (1930-1942)". In: Fausto, Boris (Org.) (1996). O Brasil republicano. v. 3. Sociedade e política (1930-1964). 6. ed., Rio de Janeiro: Bertrand Brasil, p. 341-345. (História Geral da Civilização Brasileira).

${ }^{40}$ Alves, Vágner Camilo (2002). Op. Cit., p. 56.

${ }^{41}$ Ibidem, p. 57

42 Ibidem, p. 49-50.

${ }^{43}$ Será erro grave subestimar a numerosa colônia italiana: em 1940, quando a população brasileira tocava a casa dos 40 milhões, eram 500 mil aqueles que utilizavam o italiano como língua principal do lar. Seitenfus, Ricardo (2003). O Brasil vai à guerra: o processo do envolvimento brasileiro na Segunda Guerra Mundial. 3. ed., São Paulo: Manole, p. 40.

${ }^{44}$ Seitenfus, Ricardo (2003). Op. Cit., p. 117-119.

${ }^{45}$ Alves, Vágner Camilo (2002). Op. Cit., p. 59.
} 
pagamento seria realizado com a entrega, pelo Brasil, de café, algodão, cacau, fumo, borracha e outros produtos, em que Berlim salientava especialmente seu desejo por algodão. [...] $\mathrm{O}$ aumento da demanda de algodão brasileiro na Europa fez com que a participação deste produto crescesse substancialmente no volume de exportação nacional. De uma média anual de 18.000 ton. exportadas, em fins dos anos 20 e começo dos anos 30, passou-se para 126.000 ton. em 1934, e 323.000 ton. em 1939, um aumento de quase dezoito vezes em relação ao primeiro valor apresentado. ${ }^{46}$

O avanço categórico do comércio teuto-brasileiro - em especial açúcar, borracha e algodão, principalmente este último ${ }^{47}$ - viu aproximar-se o novo conflito mundial. Em 1937, Getúlio Vargas, no uso da popularidade que fomentava e do apoio das Forças Armadas, alarmadas com a agitação comunista, promoveria mudança institucional de graves desdobramentos, inserindo o Brasil em sua terceira experiência republicana em menos de quatro décadas, o Estado Novo ${ }^{48}$. A ditadura, paulatinamente semeada desde 0 Governo Provisório e lastreada em relevantes alterações legislativas cujas raízes remontam a 1935, despia a máscara democrática e dava início a feroz repressão ${ }^{49}$.

É evidente que a trajetória de convergência comercial e política com o nazismo alemão não poderia deixar de reclamar atitude por parte dos Estados Unidos. Ainda em 1932 era despachado para o Rio de Janeiro o experiente diplomata Hugh Gibson, que dimensionaria em termos locais o firme desejo de aprofundar relações econômicas e comerciais privilegiadas: é quando terá vazão o Reciprocal Trade Agreement Act, conhecido como Programa Hull ${ }^{50}$, cujo desiderato era afastar o Novo Mundo da esfera de influência ítalo-germânica ${ }^{51}$ - no caso do Brasil, sem sucesso imediato. Com efeito, o quadro abaixo ${ }^{52}$ mostra o desenrolar dos percentuais da balança comercial brasileira em relação tanto aos Estados Unidos quanto à Alemanha:

\begin{tabular}{|c|c|c|c|c|}
\hline & \multicolumn{2}{|c|}{ Importação de } & \multicolumn{2}{c|}{ Exportação para } \\
\hline & USA & D. $^{53}$ & USA & D. \\
\hline 1933 & 21,2 & 12,0 & 46,7 & 8,1 \\
\hline
\end{tabular}

\footnotetext{
${ }^{46}$ Ibidem, p. 59-60.

47 Ibidem, p. 60.

48 Seitenfus, Ricardo (2003). O Brasil vai à guerra: o processo do envolvimento brasileiro na Segunda Guerra Mundial. 3. ed., São Paulo: Manole, p. 70.

${ }^{49}$ Fausto, Boris (2004). História do Brasil. 12. ed., São Paulo: Universidade de São Paulo, p. 364-376.

${ }^{50}$ Do secretário de Estado Cordell Hull.

51 Seitenfus, Ricardo (2003). Op. Cit., p. 84.

52 Rodrigues, José Honório; Seitenfus, Ricardo (1995). Uma história diplomática do Brasil, 1531-1945, Rio de Janeiro: Civilização Brasileira, p. 369.

${ }^{53}$ Alemanha.
} 


\begin{tabular}{|c|c|c|c|c|}
\hline 1934 & 23,7 & 14,0 & 39,5 & 13,2 \\
\hline 1935 & 23,4 & 20,4 & 39,4 & 16,5 \\
\hline 1936 & 22,1 & 23,5 & 38,9 & 13,2 \\
\hline 1937 & 23,0 & 23,9 & 36,2 & 17,1 \\
\hline 1938 & 24,2 & 25,0 & 34,3 & 17,1 \\
\hline
\end{tabular}

Da seara diplomática vem, no entanto, robusto reforço às intenções dos estadunidenses. Cansativas manobras diplomáticas e benesses pontuais ${ }^{54}$ resultam finalmente, durante as Conferências Pan-americanas de Buenos Aires (1936), Lima (1938) e Panamá (1939), em franca aceitação, por parte da expressa maioria dos países americanos, da doutrina pregada pelos Estados Unidos, segundo a qual uma agressão perpetrada contra qualquer parte do continente seria interpretada como ato hostil a cada nação que o compõe ${ }^{55}$.

Em 1939, a guerra tem início, e ainda em meados de 1940 as tropas alemãs desfilam vitoriosas em Paris. Nas novas condições postas no tabuleiro, e com interesse renovado da potência nazista ora triunfante ${ }^{56}$, ávida por livrar-se o quanto antes do bloqueio britânico ${ }^{57}$, outra delegação brasileira vai aos Estados Unidos; a política comercial norte-americana enfim é obrigada a descer de sua hesitação pretensiosa e sucumbir no ponto mais sensível:

Quando a delegação brasileira chega em Nova lorque, em 5 de agosto de 1940, os responsáveis norte-americanos estão a par das propostas de cooperação econômicas feitas ultimamente pela Alemanha, o que leva Sumner Welles a dizer que, caso as conversações germano-brasileiras com vistas à construção de um complexo siderúrgico no Brasil sejam bem-sucedidas, a "predominância alemã na vida econômica e militar brasileira estaria assegurada por vários anos". 58

Não era mais possível fazer vista grossa. É nesse ambiente de profunda desconfiança dos estadunidenses em relação às relações entre Brasil e Alemanha que se dará o recrudescimento da luta e o subsequente ataque japonês a Pearl Harbor, em 7 de dezembro de 1941. A partir daí, o assédio norte-americano se vê forçado a acentuar-se, as apostas ficam mais altas e o governo Vargas, com as mãos parcialmente atadas pelos

\footnotetext{
${ }^{54}$ Rodrigues, José Honório; Seitenfus, Ricardo (1995). Op. Cit., p. 396.

55 lbidem, p. 389-395.

56 Seitenfus, Ricardo (2003). Op. Cit., p. 225-234.

57 Alves, Vágner Camilo (2002). Op. Cit., p. 83-88.
} 
riscos do jogo, tentará tirar, na medida do possível, o máximo de proveito da aliança interamericana.

\section{A balança pende: Volta Redonda}

A explosão da guerra na Europa reordenou sem delongas o embarque da matériaprima brasileira, a qual, se antes atingia atraentes mercados europeus, agora se via quase que exclusivamente dirigida às fábricas dos Estados Unidos e, em menor proporção, às do Reino Unido, cuja marinha obviamente frustrava desembarque aberto no continente dominado pelo inimigo.

Nesse momento crítico, o manejo de tais matérias-primas já se encontrava parcialmente comprometido, em vista do acordo sobre café e algodão de 1939 e da "concessão" ao Brasil, em maio de 1941, de cotas anuais de importação, por parte dos Estados Unidos, de recursos estratégicos na seguinte medida: 100.000 toneladas de bauxita, 6.000 toneladas de cromo, 1.600 toneladas de berilo, 600 toneladas de níquel, 300.000 quilates de diamantes industriais e 500.000 toneladas de manganês ${ }^{59}$. A brusca demanda desses recursos naturais para o esforço preparatório de guerra norteamericano, manifestada ainda antes de Pearl Harbor e incrementada em seguida, leva Vargas a declarar com alívio, em 31 de dezembro de 1941, que "os mercados europeus perdidos pelo Brasil em virtude da guerra foram compensados pelo desenvolvimento do comércio com a América"60.

A preocupação mais imediata do governo brasileiro estava vencida. Sobressaía então o caldeirão político-militar em que se transformara o mundo. A expansão da Segunda Guerra Mundial para o continente americano, no final de 1941, colocara o Brasil numa situação ao mesmo tempo difícil e promissora. Se as matérias-primas em geral, primeiro quesito, tinham saída, sobrava a prioridade urdida nos meios governamentais: a questão siderúrgica.

\footnotetext{
${ }^{58}$ Rodrigues, José Honório; Seitenfus, Ricardo (1995). Op. Cit., p. 436. Sumner Welles era o subsecretário de Estado norte-americano.

${ }^{59}$ Ibidem, p. 438.

60 Ibidem.
} 
As mais respeitadas publicações historiográficas eximem de qualquer dúvida a importância conferida pelo Estado Novo ao aproveitamento do ferro brasileiro. José Honório Rodrigues escreveu:

A instalação de uma planta siderúrgica é considerada "a menina dos olhos do Brasil". No governo Vargas, dividido perante muitas questões, a questão siderúrgica imprime à equipe governamental uma aparente coesão. Como os dirigentes brasileiros vêem, em termos concretos, a questão siderúrgica? Trata-se de implantar uma usina que possa produzir, num primeiro momento, duzentos e oitenta e cinco mil toneladas de aço por ano, com investimento inicial de cerca de US\$100 milhões. ${ }^{61}$

A falta desse aporte tecnológico impedia o País de progredir em sua incipiente escalada industrial. É neste segundo quesito que se concentrará a agenda política nacional nas negociações respeitantes ao alinhamento definitivo do Brasil no cenário internacional.

Celso Lafer é convencido de que o "nacionalismo de fins" - que é como chama a política externa de Getúlio Vargas - era sustentado por vigas singulares: "o que o país podia oferecer para a condução da guerra, ou seja, matérias-primas essenciais e bases no Nordeste, importantes para a guerra na África" 62 .

Em troca dessas vantagens objetivamente arroladas por Lafer, a persistência de Vargas, enfeixada em todo o alto escalão governamental, desejava algo que os norteamericanos já haviam recusado. O primeiro contacto com a empresa United Steel fora infrutífero; porém, a notícia do jornal The New York Times de 1ํ de março de 1940, dando conta de que a alemã Krupp, velha parceira dos militares brasileiros, teria aceitado as condições postas à United Steel, deixara o governo estadunidense seriamente incomodado 63 .

A essas tratativas principais agregam-se outros elementos de igual complexidade. $O$ valor do minério de ferro, evidentemente, não ficava de lado. Ítalo Tronca ilustra:

No início de 1938, enquanto Oswaldo Aranha, ministro das Relações Exteriores, esforça-se para "reaproximar" Vargas dos Estados Unidos, acenando-lhe com uma proposta do Eximbank para financiar a usina de aço, o ministro da Viação, coronel João

\footnotetext{
61 Ibidem, p. 400.

62 Lafer, Celso (2001). Op. Cit., p. 92.

${ }^{63}$ Rodrigues, José Honório; Seitenfus, Ricardo (1995). Op. Cit., p. 400.
} 
Mendonça Lima, estabelecia contactos com a Demag alemã, para "instalar uma siderúrgica em troca de pagamento em minério brasileiro" ${ }^{64}$

Esse autor, que detalha em minúcias as marchas e contramarchas da instalação siderúrgica no Brasil, enfatiza peremptoriamente: "quase todos os projetos baseavam-se no financiamento da siderúrgica através da exportação do ferro" 65 . Outro fator que salta aos olhos é o momentâneo imediatismo do Alto Comando do Exército, então mais preocupado - naquele instante de propagação da guerra - em trocar matérias-primas por armamentos, em contraste com a visão indubitavelmente mais abrangente e de longo alcance do ditador, que não deseja entregar minérios (mormente ferro e manganês ${ }^{66}$ ) apenas em permuta por armas, mas em efetivamente ultrapassar um marco tecnológico obstativo $^{67}$.

Vargas estava, a toda evidência, ciente do impacto que tal alavanca industrial teria no desenvolvimento nacional. Em 1937, quando da proclamação do Estado Novo, mencionara a siderurgia como fator-chave para a criação de indústrias de base ${ }^{68}$. Escreveria em seu diário depois da consumação de sua vitória:

Pouco antes de recolher-me, recebi um cifrado do nosso embaixador em Washington informando que o governo americano (estava) pronto a financiar nosso programa siderúrgico. Foi uma notícia que me encheu de satisfação. É um novo teor de vida para o Brasil: a riqueza e o poder. ${ }^{69}$

Muito embora não haja unanimidade no assunto ${ }^{70}$, a estratégia do ditador, para além de outros elementos negativos de sua administração, foi decisiva para essa importante conquista da indústria nacional, a essa altura alijada de qualquer iniciativa própria ${ }^{71}$. A hesitação de Vargas entre a plataforma siderúrgica alemã e o financiamento estadunidense não parece - de uma perspectiva histórica - senão um arguto modo de obter o que sabia difícil de arrancar. Nesse contexto, o famoso discurso a bordo do encouraçado Minas Gerais em 11 de junho de 1941 - que aparentemente pendia para o totalitarismo - foi recebido com indisfarçada apreensão pelo governo norte-americano

\footnotetext{
${ }^{64}$ Tronca, Ítalo (1996). Op. Cit., p. 350.

65 Ibidem, p. 352.

66 Ibidem, p. 354.

67 Ibidem, p. 353.

68 Ibidem, p. 350.

${ }^{69}$ Apud Lafer, Celso (2001). Op. Cit., p. 93.

${ }^{70}$ Abreu, Marcelo de Paiva (1995). Op. Cit., p. 44.

71 Tronca, Ítalo (1996). Op. Cit., p. 354-355.
} 
como um todo e por Roosevelt em particular, o qual chega a duvidar das verdadeiras intenções do brasileiro $^{72}$. A desenvolta movimentação do embaixador alemão no Rio de Janeiro após tal manifestação requeria resposta firme e conclusiva. O então embaixador norte-americano no Brasil chamava-se Caffery:

Para o embaixador, havia apenas duas maneiras de combater a "crescente ameaça alemã": crédito para a aquisição de armas e um esquema liberal de financiamento para a siderúrgica. Se os alemães fornecessem as armas ou a usina, ou ambas, os Estados Unidos perderiam sua posição no Brasil. Assim, ponderava, havia chegado a hora de Washington decidir se manter o Brasil fora do controle alemão valia esse preço. Nessa época, o Brasil valia indiscutivelmente tal preço. ${ }^{73}$

A máquina administrativa dos Estados Unidos moveu-se rapidamente. Já em setembro de 1940, o Eximbank era autorizado a realizar empréstimo da ordem de 20 milhões de dólares, em condições tidas como sensivelmente favoráveis. Em abril do ano seguinte (1941), fundava-se no Rio de Janeiro a Companhia Siderúrgica Nacional, "com recursos das Caixas Econômicas do Rio e de São Paulo e dos Institutos de Aposentadoria, que contribuem com $50 \%$ do capital (250 mil contos); o governo subscreve $44 \%$ e os particulares, os restantes $6 \% " 74$.

É curioso descobrir, à luz da conclusão desse processo, que mesmo aí Vargas continua a jogar com a susceptibilidade dos norte-americanos: em 1941, expõe a irritação dos militares brasileiros com a apreensão pelos britânicos de dois navios carregados de armamentos da alemã Krupp, a fim de pleitear 100 milhões de dólares em material de guerra junto aos fabricantes dos Estados Unidos em meio à escalada da Segunda Guerra Mundial, mesmo porque o minério de ferro brasileiro continuava a ser embarcado em favor dos Aliados ${ }^{75}$.

\section{Um reflexo da guerra}

O final da Segunda Guerra Mundial, em 1945 na Europa e em 1946 no Pacífico, trouxe sensível desconforto ao Estado Novo. Brasileiros tinham ido à Europa - e agora

\footnotetext{
72 Ibidem, p. 356.

73 lbidem, p. 357.

74 lbidem.

75 Ibidem, p. 357-358.
} 
voltavam - para defender a democracia representativa do fascismo, enquanto paradoxalmente seu próprio país vivia um regime político repleto de características de todas as cores, à exceção das democráticas. A deposição de Vargas, em 1945, seria um desenrolar quase que natural da preponderância a que normalmente se arrogam as forças armadas dos países beligerantes nas respectivas políticas internas com a consagração da vitória.

No plano internacional, as autoridades brasileiras, no movimento pendular tão característico da política nacional, tentaram estreitar laços com a antiga potência aliada, o Reino Unido, até como contrapeso à agora exuberante influência norte-americana. Havia ambiente propício, dado que os Estados Unidos se mostravam "bastante menos generosos em relação ao Brasil do que havia sido o caso nos anos iniciais da guerra, quando os seus objetivos políticos e econômicos na América do Sul ainda não haviam sido alcançados"76. O preço do café, por exemplo, teve pedidos de majoração sistematicamente negados pela administração Truman, concomitante ao fato de mostrarse o novo governo estadunidense crescentemente insatisfeito com a política de substituição de importações, deveras prejudicial a importantes setores industriais da América do Norte $^{77}$. Mais além, a hostil política antiargentina expressada pelos Aliados no pós-guerra começou a parecer extremada mesmo às autoridades brasileiras, normalmente propensas a celebrar os constrangimentos do vizinho ${ }^{78}$.

Tal tentativa, porém, não obteve sucesso, à vista do fato de que a influência dos Estados Unidos só fez aumentar, tanto por parte da pressão social por democracia, quanto do lado militar, que testemunhara na guerra o poderio material irresistível dos norte-americanos. O Exército, aliás, seria um componente essencial para a instauração de um regime institucionalmente democrático, economicamente liberal e politicamente conservador a partir da Constituição de $1946^{79}$, que num primeiro momento alinharia a política externa do Brasil inteiramente aos paradigmas estadunidenses ${ }^{80}$.

\footnotetext{
${ }_{77}^{76}$ Abreu, Marcelo de Paiva (1995). Op. Cit., p. 46.

77 Ibidem.

78 lbidem.

79 Bonavides, Paulo; Andrade, Paes de (2004). História constitucional do Brasil. 5. ed., Brasília: OAB, p. 416.

${ }^{80}$ Abreu, Marcelo de Paiva (1995). Op. Cit., p. 47.
} 
Para os fins expostos, contudo, interessa examinar, em linhas gerais, o reflexo econômico da guerra para o Brasil no tocante à exportação de recursos naturais, já que sua economia dependia, em grande medida, dessa atividade.

É o que faz Caio Prado Júnior, que exprime característica determinante da exportação de matérias-primas durante a guerra:

No curso da guerra, sobretudo em sua última fase e prolongando-se nos anos subseqüentes, assistimos a um revigoramento esporádico do tradicional sistema do passado, abrindo-se para tal sistema (isto é, uma economia exportadora de produtos primários e voltada essencialmente para o exterior), nova e brilhante oportunidade. Com uma intensidade de que havia muito o país não tinha notícia, o Brasil se fazia de novo alvo de forte demanda internacional de gêneros alimentares e matérias-primas exigidos agora pelas necessidades da luta em que se empenhavam as grandes potências de que 0 Brasil era e ainda é tributário. ${ }^{81}$

O aumento, todavia, não se daria exatamente no volume, mas no preço pago pelo produto $^{82}$. O caso típico foi a borracha do látex, cuja produção não chegou a dobrar, mas experimentou vertiginoso aumento de preço depois da ocupação das regiões produtoras do Oriente:

Essa intensificação da demanda não se reflete tanto no volume da exportação, cujo aumento não será muito sensível. Circunstância que devemos notar desde já e que mostra o esgotamento da capacidade produtiva da economia brasileira de exportação. Mas no valor, o efeito será considerável, ascendendo a exportação brasileira de gêneros alimentícios e matérias-primas para altos níveis. ${ }^{83}$

É de se destacar, também, no período, certa variação da atividade extrativa, inaugurando - entre outras - a silvicultura em grande escala ${ }^{84}$. À parte o seriíssimo problema inflacionário interno causado pela assimetria da demanda durante a guerra e logo após, tanto de produtos primários quanto de bens industrializados ${ }^{85}$, as variáveis apontadas determinariam sensíveis mudanças no quadro fiscal do Estado: o aumento da exportação e a diminuição das importações - outra consequência quase que imediata do estado de guerra - elidiriam por algum tempo o crônico desequilíbrio da balança

\footnotetext{
${ }^{81}$ Prado Júnior, Caio (1998). Op. Cit., p. 302.

${ }^{82}$ Furtado, Celso (1961). Op. Cit., p. 231.

83 Prado Júnior, Caio (1998). Op. Cit., p. 302.

84 Ibidem.
} 
comercial brasileira $^{86}$, fator reputado importantíssimo para a estabilidade política do regime inaugurado em 1946, ainda sensivelmente preso à remessa de recursos naturais para o exterior.

\section{Considerações finais}

Em termos históricos, o "nacionalismo de fins" de Vargas revela-se em certo sentido como germe da política externa posta em prática por alguns de seus sucessores, como Juscelino Kubitschek, Jânio Quadros - considerado "de direita" - e levada adiante pelo vice que Ihe assumiu as funções, João Goulart - tido com "de esquerda": a "política externa independente" 87 .

"Em Roma como os romanos", ensina a sabedoria popular. Muito embora todos os acontecimentos referentes à Segunda Guerra Mundial, por sua proporção, fossem extraordinários, a maneira com que o governo brasileiro levara toda negociação de vulto, desde os acordos de exportação de recursos naturais até a fundação da Companhia Siderúrgica Nacional, representou sem dúvida uma inflexão no padrão de tratamento dos recursos naturais nacionais, alçados pela primeira vez à condição de propulsores decisivos do desenvolvimento.

Até aquele momento - e, segundo algumas vozes, até hoje - os condutores da política externa nacional permanecem numa postura passiva, senão submissa, aos ditames dos interesses de momento dos consumidores dos recursos naturais brasileiros, alguns dos quais estratégicos ao extremo, como o ferro e o manganês, além de subestimar a forte demanda por produtos agrícolas como o algodão e o açúcar de outrora, a soja e o etanol de hoje. Esse procedimento governamental, que se manifesta com pequenas variações de tonalidade, vem de longe. Ao discursar sobre a nacionalidade brasileira, Joaquim Nabuco declarou: "O Brasil sempre teve consciência de seu tamanho e tem sido governado por um sentimento profético de seu futuro"88.

O estudo do precedente de manejo dos recursos naturais e dos produtos primários nacionais no conflito maior não implica ingênuo e irrestrito aplauso a Vargas como um

\footnotetext{
${ }^{85}$ Furtado, Celso (1961). Op. Cit., p. 232-239.

${ }^{86}$ Prado Júnior, Caio (1998). Op. Cit., p. 303.

${ }^{87}$ Lafer, Celso (2001). Op. Cit., p. 97.

${ }^{88}$ Apud Lafer, Celso (2001). Op. Cit., p. 7.
} 
sagaz e altivo patriota que conseguiu lograr as malvadas potências imperialistas; mas ele, ao contrário de outros que já enfeixaram poder análogo ao que exerceu, era concretamente pragmático ${ }^{89}$ e claramente soube perceber, por exemplo, a situação de momentânea desvantagem da Alemanha ${ }^{90}$ no consumo das diversas matérias-primas que há tempos importava do Brasil.

O ditador brasileiro, além de jamais pôr em risco de soçobrar, de modo irreversível, a relação com o poderoso vizinho norte-americano, desempenhou com razoável desembaraço o intenso comércio com a Europa Central, sem sequer ameaçar, lembre-se, seu controle absoluto sobre a numerosa minoria alemã presente no Brasil, muitas vezes à custa do orgulho do Terceiro Reich, como lembra com interesse Vágner Camilo Alves:

Esta visão mais ampla dos interesses alemães no Brasil, somada aos imperativos ditados pela geografia e pela distribuição de poder relativo em nível mundial, explica por que um governo tão incisivo e violento em sua política exterior aceitou que um país fraco e periférico lhe impusesse o que podemos definir como pequenas humilhações políticas, como a defenestração do Partido Nacional-Socialista de seu território nacional, e a declaração do embaixador alemão como persona non grata, atitudes que, caso provindas de algum pequeno Estado dos Bálcãs, certamente teriam ensejado resposta muito mais forte. ${ }^{91}$

Sem sufragar nem os métodos nem os fins de Getúlio Vargas e dos mais capazes integrantes de sua administração, como Oswaldo Aranha, não é possível deixar de reconhecer a desenvoltura internacional do caudilho, que se provou capaz de impor condições ao uso militar do território brasileiro, culminando com a transferência de divisas e de tecnologia, o que possibilitou, especialmente, a criação da Companhia Siderúrgica Nacional.

O exemplo do bom não é modelo do melhor, mas não deixa de ser reconfortante, quando se observam as últimas décadas da política externa nacional, relembrar posturas

\footnotetext{
${ }^{89}$ Pereira, Raquel Maria Fontes do Amaral (2005). "A Revolução de 30: lições para a saída da crise brasileira atual". In: Encontro de Geógrafos da América Latina, 10., 2005, São Paulo. Anais do X Encontro de Geógrafos da América Latina, São Paulo: Departamento de Geografia FFLCH Universidade de São Paulo, p. 11.724.

${ }^{90}$ Alves, Vágner Camilo (2002). Op. Cit., p. 196-197.

${ }^{91}$ Ibidem, p. 67.
} 
consistentes e capazes de vencer o retrato sarcástico que Mário de Andrade traçou do Brasil: "bloco pachola do 'Custa mas vai!'”92.

\section{Referências}

Abreu, Marcelo de Paiva (1995). "O Brasil e a economia mundial (1929-1945)”. In: Fausto, Boris (Org.) (1995). O Brasil republicano. v. 4. Economia e cultura (1930-1964). 3. ed., Rio de Janeiro: Bertrand Brasil. (História Geral da Civilização Brasileira)

Almeida, Paulo Roberto de (2002). Os primeiros anos do século XXI: o Brasil e as relações internacionais contemporâneas, São Paulo: Paz e Terra.

Alves, Vágner Camilo (2002). O Brasil e a Segunda Guerra Mundial: história de um envolvimento forçado, Rio de Janeiro: PUC-Rio; São Paulo: Loyola.

Bonavides, Paulo; Andrade, Paes de (2004). História constitucional do Brasil. 5. ed., Brasília: OAB.

Buescu, Mircea (1977). Evolução econômica do Brasil, São Paulo: Brasiliense.

Dean, Warren (1997). "A industrialização durante a República Velha”. In: Fausto, Boris (Org.). (1997). O Brasil republicano. v. 1. Estrutura de poder e economia. 6. ed., Rio de Janeiro: Bertrand Brasil, 1997. (História Geral da Civilização Brasileira)

Fausto, Boris (1997). "Expansão do café e política cafeeira”. In: Fausto, Boris (Org.) (1997). O Brasil republicano. v. 1. Estrutura de poder e economia. 6. ed., Rio de Janeiro: Bertrand Brasil. (História Geral da Civilização Brasileira) . (2004). História do Brasil. 12. ed., São Paulo: Universidade de São Paulo.

Furtado, Celso (1961). Formação econômica do Brasil. 4. ed., Rio de Janeiro: Fundo de Cultura.

Gnaccarini, José C. (1997). "A economia do açúcar. Processo de trabalho e processo de acumulação". In: Fausto, Boris (Org.) (1997). O Brasil republicano. v. 1. Estrutura de poder e economia. 6. ed., Rio de Janeiro: Bertrand Brasil. (História Geral da Civilização Brasileira)

Hakim, Peter (2004). "The reluctant partner". In: Foreign Affairs, Nova Iorque, v. 83, n. 1, p. 114-23, jan./fev.

Hobsbawm, Eric (1995). Era dos extremos: o breve século XX: 1914 - 1991. Tradução de Marcos Santarrita, São Paulo: Companhia das Letras.

${ }^{92}$ Apud Lafer, Celso (2001). Op. Cit., p. 7. 
Keynes, John Maynard (2002). As conseqüências econômicas da paz. Tradução de Sérgio Bath, Brasília: Universidade de Brasília, Instituto de Pesquisa de Relações Internacionais; São Paulo: Imprensa Oficial do Estado de São Paulo.

Lafer, Celso (2001). A identidade internacional do Brasil e a política externa brasileira: passado, presente e futuro, São Paulo: Perspectiva, p. 27.

Pereira, Raquel Maria Fontes do Amaral (2005). "A Revolução de 30: lições para a saída da crise brasileira atual". In: Encontro de Geógrafos da América Latina, 10., 2005, São Paulo. Anais do X Encontro de Geógrafos da América Latina, São Paulo: Departamento de Geografia FFLCH Universidade de São Paulo.

Powell, Colin L. (2004). "A strategy of partnership”. In: Foreign Affairs, Nova lorque, v. 83, n. 1, p. 22-34, jan./fev.

Prado, Maria Lígia Coelho; Capelato, Maria Helena Rolim (1997). "A borracha na economia brasileira da Primeira República". In: Fausto, Boris (Org.) (1997). O Brasil republicano. v. 1. Estrutura de poder e economia. 6. ed., Rio de Janeiro: Bertrand Brasil. (História Geral da Civilização Brasileira)

Prado Júnior, Caio (1998). História econômica do Brasil. 45. reimpr., São Paulo: Brasiliense.

Renouvin, Pierre; Duroselle, Jean-Baptiste (1967). Introdução à história das relações internacionais, São Paulo: Difusão Européia do Livro.

Rodrigues, José Honório; Seitenfus, Ricardo (1995). Uma história diplomática do Brasil, 1531-1945, Rio de Janeiro: Civilização Brasileira.

Seitenfus, Ricardo (2003). O Brasil vai à guerra: o processo do envolvimento brasileiro na Segunda Guerra Mundial. 3. ed., São Paulo: Manole

Tronca, Ítalo (1996). "O Exército e a industrialização: entre as armas e Volta Redonda (1930-1942)". In: Fausto, Boris (Org.) (1996). O Brasil republicano. v. 3. Sociedade e política (1930-1964). 6. ed., Rio de Janeiro: Bertrand Brasil. (História Geral da Civilização Brasileira) 